I 16.2$]$

\title{
Editor's Column: The Struggle with the Angel- On Submitting Work to PMLA
}

AM SITTING IN MY OFFICE ABOUT TO GO OVER, FOR THE first time, the manuscripts of the four regular essays that will appear in the March 2001 issue of $P M L A$, the one that you, the reader, are now holding. They were all chosen for publication before I assumed the duties of editor on 1 July of last year. Hence, I am about to encounter completely unfamiliar texts, just as you will when you go on to read-I hope-the contents of this issue.

This unfamiliarity starkly contrasts with the sense of intimacy that binds me to the essays that will appear in subsequent issues, over which I labored and pored in preparation for the two meetings of the Editorial Board that I have chaired so far. That investment has been increased by the lively and protracted discussions that these manuscripts elicited among the board members, by the correspondence generated in the aftermath of those meetings, in which detailed recommendations for revisions were sent even to authors whose articles sailed through the process, and by the careful reading of the authors' final versions before copyediting began. When these articles finally appear in print, $I$ will be able to recognize in them the traces of a personal involvement that, for better or worse, will be strewn throughout the issue's pages.

There is nothing especially significant about this experience, except as a particular installment of a much broader circumstance that we have all faced at some point or another. It is the feeling we invariably have when inserting ourselves into a process, an institution, or a tradition that existed before we joined it, whether by will or necessity. In such a situation, you feel tension between your subjectivity and a seemingly impersonal order outside it that resists it on account of its pretensions to singularity and exclusivity. 
A circumstance like this one invites two fundamental attitudes in response. We can choose to abandon ourselves to the structural dimension of the situation - to the knowledge that others have been in this position before and that others will doubtless be in it in the future as well. Or we can choose to underscore what is unique about this particular juncture in spite of its repetition and repeatability. The first attitude offers a certain amount of peace, the serenity that issues whenever we assume the longue durée perspective: in the larger scheme of things, not much of real consequence is riding on one's performance, for a long series extends in both directions in time and turns that performance into a mere link in a chain. Conversely, the second perspective saddles us with the responsibility to make a mark, the anxiety to be original, to change the course of events somehow through personal investment and toil.

Becoming the editor of a long-standing journal such as PMLA summons the first of these impulses with unusual force. The sheer institutional weight and prestige of the publication give its current look, editorial practices, and features an extraordinary momentum. For while it is true that you have been entrusted with the journal's direction for a time, it is equally true that the first order of business is to accommodate yourself to its demanding rhythms and schedules. Indeed, I would venture that all new editors of PMLA have had a realization akin to the one described by the Argentine writer Julio Cortázar in his "Preamble to the Instructions on How to Wind a Watch":

Think of this: When they give you a watch as a present they are giving you a tiny flowery hell, a chain of roses, a dungeon of air. They aren't simply giving you a watch, may you have many more, and we hope it will last you, it's a good brand, Swiss with jeweled mechanism; they aren't just giving you this minute stonecutter which you will strap around your wrist and you will take along with you. They are giving youthey don't know it, it's terrible that they don't know it-they are giving you a new, fragile, and precarious piece of yourself, something that's yours but not a part of your body, that you have to strap to your body with its belt like a tiny desperate arm hanging from your wrist. They give you the job of having to wind it every day, the obligation to wind it so that it goes on being a watch; they give you the obsession of checking the exact time in jewelry-shop windows, in radio announcements, in the telephone service. They give you the gift of fear, that someone will steal it from you, that it will fall on the street and break. They give you the gift of its brand and the assurance that it's a brand better than the others, they give you the impulse to compare your watch with other watches. They aren't giving you a watch: you are the gift, they're giving you to the watch for the watch's birthday.'

Furthermore, the intellectual and professional satisfactions derived from close association with the journal are so immediate and enticing that they can easily lull you into simply marking time. The frequent and intense exchanges of ideas, the pleasure of working with an extraordinarily intelligent and professional staff that seemingly never takes a misstep, and the quiet satisfaction felt whenever the latest issue appears all combine to create a rush of sorts and a happy dependence on it with which you do not wish to meddle.

Inevitably perhaps, the contrary impulseto channel all that energy in a way that leaves an imprint of your season at the helm-eventually demands its due. The handsome, vibrant journal that PMLA is nowadays is the result of my predecessors' single-minded efforts to steer the publication toward uncharted destinations. Their contributions become even more impressive when one considers the narrow latitude that the editor of PMLA has in effecting changes of any sort in the journal, since all such proposals have to be vetted first by the Editorial Board and later by the association's Executive Council. Anyone who has at hand old issues of PMLA will be able to discern immediately the profound manifestations of the personal effort invested by those who preceded me, of their desire to overcome the 
journal's institutional will to remain unaffected by whatever transient is editor. They successfully identified points of articulation where applying the right amount of pressure made possible significant changes in the journal's dominant purpose and immediate appearance-its ser and estar, as one would say in Spanish.

It occurs to me that prospective contributors to PMLA find themselves in the same situation vis-à-vis the review. The lore of the profession perpetuates a well-entrenched, monolithic view about $P M L A$ : its dauntingly complicated evaluation process, its monologic genuflection to trends, the glacial speed at which its editorial decisions are rendered, its preference for manuscripts of a certain kind or another, and so on. I could spend a great deal of ordnance and time rebutting each of these, but the exercise would be ultimately moot, since we are dealing with perceptions that have been shaped by the accumulated weight of anecdotal evidence and professional gossip. Furthermore, a journal that by its nature has to satisfy the demands and represent the interests of such a large and heterogeneous membership is fated to please no one fully. But it must be kept in mind that precisely this requirement sets PMLA apart from other journals and determines its laudable yet impossible objective to serve as a clearinghouse for ideas and concerns issuing from irreducibly different quarters. PMLA is a house divided against itself, yet it must not merely stand but also thrive. Indeed, I would argue that the journal's notoriety as a difficult, resisting venue for publication is related to its need to harness many centrifugal forces that threaten it with dispersion. Hence, the journal's resistance- which is felt as its desire to remain unchanged and which hypostatized into the foreboding conception that the membership has of it-is systemic, yet it is directed not at any one kind of submission but at the pressure exerted by all submissions collectively. Paradoxically, PMLA's strength stems directly from how well it manages both to sustain and to survive this predicament from one issue to the next.
If this dynamic of health through fruitful antagonism is to maintain itself, though, all fields, constituencies, critical ideologies, and special interests must find their way to the journal. This is, of course, the point at which an editor's responsibilities and influence end and those of potential contributors begin. The current dearth of submissions to PMLA is worrisome principally because it signals the increasing unwillingness of the members of the association to enter into this dialectic. The contest of wills between a medium that resists and a subjectivity that wishes to leave an imprint in it is apparently no longer perceived as a fair game. In the collective mind of the profession, PMLA has, in that essential contest, acquired an overwhelming superiority that seemingly leaves little room for individual agency to transform the journal, however slightly. Since the dynamic is attendant on PMLA because of its nature as a forum for a richly heterogeneous collection of fields, constituencies, and approaches, there is little that its ruling bodies can do to alter the dialectic, except to understand and to express at every turn that this dynamic demands the journal's unwavering commitment to openness. But above all, those in a position to submit their work to the journal must be willing to engage the process, because the refusal of even one member to do so impoverishes the outcome.

For PMLA to serve its raison d'être, potential contributors have to develop a more instrumental conception of their relation to the journal. Instead of asking themselves, for instance, how they may adjust their work to accommodate it to PMLA, they should ponder how the journal might serve as a forum for their ideas or for the issues salient in their fields. From this perspective, even manuscripts that are declined have the power to modify the journal, inasmuch as they can change the consultant readers' and the Editorial Board's sense of the discipline as a whole and of the issues that preoccupy or define any of its constituencies. Hence, the investment in PMLA by all members of the association goes beyond whether their submissions meet with a 
happy outcome. It has far more to do with ensuring that the journal becomes a truly capacious forum in which none of the voices that make up our discipline goes unrepresented. I am proposing not that authors should feel cheerful about receiving a letter of rejection from PMLA but rather that, because of the journal's nature, there is a surfeit of meaning and significance in the simple act of submission that changes the narrow teleological interpretation of the event.

As chance would have it, the four superb articles gathered in this issue have as their common horizon the exploration of various forms of affect as embodiments of discrete ideological negotiations. Each depicts, in its distinct fashion, a dialogic struggle in which there is much at stake: between subjectivities, between individuals and external forces, between texts and state ideology, or between the critical tradition and a new reading that challenges it. In "The Seducer as Friend" Dawn Marlan discusses the paradoxical mechanism through which mastery of the other is signaled in Laclos's Les liaisons dangereuses. Stacey Margolis argues in "Huckleberry Finn; or, Consequences" for a novel reading of the evolving relationship between Huck and Jim that takes to task the two principal canonical interpretations of that evolution. In "Henry James's Oblique Possession" Gert Buelens identifies a discourse of self-mastery that founds itself in the contradictory surrender to the demands of an outside force. And Barbara Fuchs's "Empire Unmanned" reads a gender-coded critique of Spanish imperialist pretensions in Cervantes's novella "Las dos doncellas."

But, more generally, their inclusion in this issue is the result of their authors' willingness to engage in another struggle-with the journal's reputation as a difficult, resistant avenue for publication. They each entered into negotiation with $P M L A$, a medium that simultaneously beckons and challenges, and in the end managed to inscribe in it themselves, their work, and preoccupations specific to their fields. They struggled resolutely with the angel until dawn, and just as in the biblical story, both parties left the arena wiser and more knowing.

Cortázar's "Preamble to the Instructions on How to Wind a Watch" is followed, naturally. by "Instructions on How to Wind a Watch." Given the instrumentality that I am arguing contributors should entertain in their dealings with $P M L A$, the text is a fitting conclusion to these musings on the affect, the mutual obligation. that binds the journal and all the members of the association that it represents:

Death is there in the background, but don't be afraid. Hold the watch down with one hand, take the stem in two fingers, and rotate it smoothly. Another installment of time opens now, trees spread their leaves, boats run races, time continues filling with itself like a fan, and from it burgeon the air, the breezes of the earth. the shadow of a woman, the sweet smell of bread.

What did you expect, what more do you want? Quickly strap it to your wrist, let it tick away in freedom, imitate it greedily. Fear rusts all the jewels, everything that was within reach and was abandoned corrodes the watch's veins. cankering the cold blood of its tiny rubies. And death is there in the background if we don 't hurry to arrive beforehand and understand it doesn't matter anymore.

Wind that watch without fear: submit your best work to PMLA.

Carlos J. Alonso

\section{NOTE}

${ }^{1}$ I have made changes in the translation.

\section{WORK Cited}

Cortázar, Julio. Cronopios and Famas. Trans, Paul Black burn. New York: Pantheon, 1969. 